\title{
Tumor suppressor microRNA-34a inhibits cell migration and invasion by targeting MMP-2/MMP-9/FNDC3B in esophageal squamous cell carcinoma
}

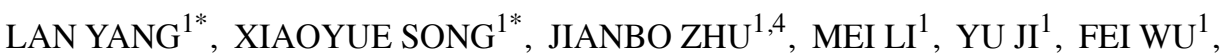 \\ YUNZHAO CHEN $^{1}$, XIAOBIN CUI ${ }^{1}$, JIANMING HU ${ }^{1}$, LIANGHAI WANG ${ }^{1}$, \\ YUWEN CAO $^{1}$, YUTAO WEI ${ }^{2}$, WENJIE ZHANG ${ }^{1}$ and FENG LI ${ }^{1,3}$
}

\author{
${ }^{1}$ Department of Pathology and Key Laboratory for Xinjiang Endemic and Ethnic Diseases, \\ Shihezi University School of Medicine; ${ }^{2}$ The First Affiliated Hospital, Shihezi University School of Medicine, \\ Shihezi, Xinjiang; ${ }^{3}$ Department of Pathology, Beijing ChaoYang Hospital, Capital Medical University, \\ Beijing; ${ }^{4}$ The Second Affiliated Hospital, Third Military Medical University, Chongqing, P.R. China
}

Received January 27, 2017; Accepted May 12, 2017

DOI: $10.3892 /$ ijo.2017.4015

\begin{abstract}
MicroRNAs (miRNAs) are a large family of small, non-coding RNAs that play a pivotal role in tumorigenesis. miR-34a, which is a member of the miR-34 family, is a downstream target of $\mathrm{p} 53$. Increasing evidence shows that miR-34a dysregulation may contribute to tumor development and progression in numerous cancers, including esophageal squamous cell carcinoma (ESCC). However, the mechanism of miR-34a in the regulation of ESCC cells need to be further elucidated because of the complex regulative network of miRNAs. The miR-34a expression in ESCC samples has been
\end{abstract}

Correspondence to: Dr Lan Yang, Department of Pathology, Shihezi University School of Medicine, 59 North 2nd Road, Shihezi, Xinjiang 832002, P.R. China

E-mail: yl-branda@163.com

${ }^{*}$ Contributed equally

Abbreviations: miRNA, microRNA; miR-34a, microRNA 34a; ESCC, esophageal squamous cell carcinoma; MMP-9, matrix metalloproteinase-9; MMP-2, matrix metalloproteinase-2; FNDC3B, fibronectin type III domain containing 3B; mRNAs, messenger RNAs; 3'-UTR, 3'-untranslated region; 5'-UTRs, 5'-untranslated regions; EMT, epithelial-mesenchymal transition; YY-1, Yin Yang-1; PCR, polymerase chain reaction; real-time RT-PCR, real-time reverse transcription PCR; FFPE, formalin-fixed and paraffinembedded; DMEM, Dulbecco's modified Eagle's medium; FBS, fetal bovine serum; qRT-PCR, quantitative reverse transcription PCR; cDNA, complementary deoxyribonucleic acid; PBS, phosphate buffered saline; TGF $\beta 1$, transforming growth facor $\beta 1$; CDs, coding region; Tris, trihydroxymethylaminornethane

Key words: esophageal squamous cell carcinoma, miR-34a, migration and invasion, matrix metalloproteinase $2 / 9$, fibronectin type III domain containing $3 \mathrm{~B}$ confirmed using quantitative reverse transcription polymerase chain reaction. The effects of miR-34a on cell migration and invasion were examined in ESCC cell lines using wound healing and Transwell assays, respectively. The effects of miR-34a on matrix metalloproteinase (MMP)-2 and -9 and fibronectin type III domain containing 3B (FNDC3B) expression levels were detected by luciferase reporter assays and western blot analysis. Quantitative polymerase chain reaction revealed that the miR-34a expression is significantly downregulated in the ESCC tissues compared to that in the adjacent normal tissues. miR-34a overexpression was significantly suppressed migration and invasion in the ESCC cells and simultaneously inhibited the MMP-2, MMP-9 and FNDC3B expression levels by targeting the coding and 3'-untranslated regions, respectively. The findings indicated that microRNA-34a suppresses cell migration and invasion by targeting MMP-2, MMP-9, and FNDC3B in ESCC.

\section{Introduction}

Esophageal squamous cell carcinoma (ESCC) is one of the most frequent malignant tumors in China (1). Some advances have been made in the treatment of ESCC, including surgery, chemotherapy, radiation, or a combination of these options. However, the associated prognosis of ESCC patients is still not satisfactory. The five-year overall survival rate of ESCC patients after surgery is only approximately $14-22 \%$ (2-4). Tumor invasion and metastasis are the major causes of the poor prognosis of ESCC patients $(5,6)$. Some oncogenic and tumor suppressive factors have been reported to be associated with ESCC progression. However, only a few of them are specific and conclusive $(7,8)$. Therefore, exploring the detailed molecular mechanisms of ESCC cell progression, invasion, and metastasis will help improve disease diagnosis and therapy.

MicroRNAs (miRNAs) are endogenously expressed, small, non-coding RNAs of 19-24 nucleotides that regulate gene expression by either inhibiting translation or cleaving their 
target messenger RNAs (mRNAs) $(9,10)$. The miRNA target site is considered to be the 3'-untranslated region (3'-UTR) of mRNA. Mounting evidence shows that miRNAs may also bind coding or 5'-untranslated regions (5'-UTRs) (11-15). Evidence also shows that miRNAs are involved in the pathogenesis of most cancer, such as cell differentiation, proliferation, oncogenesis, angiogenesis, cell migration, and invasion, where some can function as tumor suppressors or oncogenes (16-19). The aberrant regulation of miRNAs has been shown involved in numerous cancers, including $\operatorname{ESCC}(4,14)$.

MicroRNA-34a (miR-34a), which is located in chromosome $1 \mathrm{p} 36$ and belongs to the miR-34 family, is directly regulated by the p53 transcription factor (20). miR-34a is more commonly downregulated than the non-malignant tissues in multiple cancers, such as tongue squamous cell carcinoma (12), non-small cell lung cancer (21), colon cancer (22), pancreatic cancer (23), and others (24-26). miR-34a in cancer has also been extensively studied in tumor growth, migration, invasion, and epithelial-to-mesenchymal transition (EMT). Accordingly, miR-34a has been reported to suppress cell proliferation, migration, invasion, and EMT in various cancer cells by targeting oncogenes (22-24,27-31). miR-34a modulates stem cell self-renewal and difference in multiple cancers $(23,25,32$ 35). In addition, miR-34a regulates drug resistance (36-38), and has been suggested to act as a suppressor that plays a key role in tumorigenesis. However, the role that miR-34a plays in ESCC is still in question. One recent study found that miR-34a could inhibit ESCC cell migration and invasion by targeting Yin Yang-1 (YY-1). YY-1 can suppress the matrix metalloproteinase (MMP)-2 and -9 expression levels (39). However, miR-34a is reported to inhibit cell migration and invasion by directly targeting MMP-9 in tongue squamous cell carcinoma (12). Therefore, whether miR-34a can directly target MMP-9 or MMP-2 to regulate ESCC cell migration and invasion needs to be investigated. The detailed role and mechanism of miR-34a in ESCC cell regulation needs to be further elucidated.

This study evaluated the miR-34a and p53 expression in ESCC tumor tissues and adjacent normal tissues. It shows that miR-34a and p53 both significantly decreased in the ESCC tissues. Moreover, the expression of p53 and miR34a has positive correlation in ESCC tissues. We further verified the functional role for miR-34a in ESCC cell invasion and migration. The regulative network of miR-34a in ESCC cancer was also explored. The obtained data indicate that miR-34a suppressed ESCC cell invasion and migration. Our study also demonstrates that MMP-2/MMP-9/fibronectin type III domain containing $3 \mathrm{~B}$ (FNDC3B) is a direct downstream target of miR-34a, and miR-34a overexpression in the ESCC cells decreases both mRNA production and protein expression of MMP-2/MMP-9/FNDC3B. miR-34a suppressed tumor cell invasion and migration in ESCC by suppressing MMP-2 and MMP-9/FNDC3B expression levels.

\section{Materials and methods}

Ethics statement. The experiments were approved by the Institutional Ethics Review Board of the First Affiliated Hospital of the Shihezi University School of Medicine. All samples were obtained from patients who signed informed consent forms approving the use of their tissues for research purposes after surgery.

Human tissue samples and cell lines. A total of 15 normal esophageal and 15 human ESCC tissues were used for realtime polymerase chain reaction (PCR) analysis. All tissue specimens were obtained from the First Affiliated Hospital of Shihezi University. All tissues were formalin-fixed and paraffin-embedded (FFPE) for pathological diagnosis. The normal esophageal tissues were obtained from a distance of $\geq 5 \mathrm{~cm}$ from the tumor tissues.

The ESCC cell lines used, including EC9706 and TE-1, were purchased from the Shanghai Institute of Biochemistry and Cell Biology (Shanghai, China). HEK293 was a gift from the biochemical laboratory (American Type Culture Collection) of the Shihezi University School of Medicine. All cells were cultured in Dulbecco's modified Eagle's medium (DMEM) (Gibco) supplemented with $10 \%$ heat-inactivated fetal bovine serum (FBS; BI), $100 \mathrm{U} / \mathrm{ml}$ penicillin, and $100 \mu \mathrm{g} / \mathrm{ml}$ streptomycin in a humidified incubator containing $5 \% \mathrm{CO}_{2}$ at an atmosphere of $37^{\circ} \mathrm{C}$.

$R N A$ isolation and quantitative reverse transcription $P C R$ ( $q R T-P C R)$. The total RNA, including miRNA, was isolated from the FFPE and cell samples using the miRNeasy FFPE (no. 73504) and miRNeasy Mini (no. 217004) kits from Qiagen (Hilden, Germany). The kits were used according to the manufacturer's instructions. The concentration and purity of the RNA samples were measured using NanoDrop2000 (Thermo Scientific). The RNA was reverse transcribed into cDNA using the miScript II Reverse Transcription (RT) kit (no. 218161) from Qiagen according to the manufacturer's protocol with $1000 \mathrm{ng}$ total RNA. Subsequently, qRT-PCR was conducted using the SYBR Green PCR kit (miScript SYBR Green PCR kit for miRNA; no. 218073; Qiagen) and the QuantiFast SYBR Green PCR kit for mRNA (no. 204054; Qiagen) containing ROX as the reference dye in the ABI 7500 RT-PCR system. The PCR primers for miR-34a (Hs_miR-34a_1 miScript primer assay, MS00003318), U6 (Hs_RNU6-2_1 miScript primer assay, MS00033740), and ACTB (encoding $\beta$-actin) (Hs ACTB_1_SG, QT00095431) were purchased from Qiagen. The MMP-2, MMP-9, and FNDC3B primers were synthesized (Applied Sangon Biotech Co., Ltd., Shanghai, China). The sequences were as follows: MMP-2 forward, 5'-TATGGCTTCT GCCCTGAGAC-3' and MMP-2 reverse 5'-CACACCACATC TTTCCGTCA-3'; MMP-9 forward, 5'-CGAACTTTGACAG CGACAAG-3' and MMP-9 reverse, 5'-CGGCACTGAGGAA TGATCTA-3'; and FNDC3B forward, 5'-TTGGAGAGGG AATGGTGTTT-3' and FNDC3B reverse 5'-CAGGTCACGC AGCAAGTTAG-3'. Accordingly, U6 and $\beta$-actin were used as internal control for the normalization and quantification of the miRNA and mRNAs, respectively. Quantification was performed in triplicate.

miR-34a mimic/inhibitor transfection. The chemically synthesized miR-34a mimic (Syn-hsa-miR-34a-5p miScript miRNA mimic, MSY0000255), miR-34a inhibitor (Antihsa-miR-34a-5p miScript miRNA inhibitor, MIN0000255), and negative controls (AllStars Negative Control siRNA, no. 1027280; miScript inhibitor negative control, no. 1027271) 
were purchased from Qiagen. The ESCC cells were transfected with miR-34a mimic $(10 \mathrm{nM})$ for miR-34a overexpression or with miR-34a inhibitor ( $50 \mathrm{nM}$ ) for miR-34a inhibition by Hiperfect (no. 301705; Qiagen) according to the manufacturer's instructions.

Wound healing assay. A total of $30 \times 10^{4}$ ESCC cells were cultured in one 6-well culture plate. These cells were transfected with different concentrations of miR-34a mimic (10 nM) for overexpression or miR-34a inhibitor $(50 \mathrm{nM})$ for inhibition using Hiperfect for $24 \mathrm{~h}$. The transfection allowed cells to reach full confluence. The confluent cells were subsequently wounded by scraping using a $10 \mu \mathrm{l}$ pipette tip. The dislodged cells were removed by washing with a serum-free medium. The cells that migrated into the wounded area or protruded from the wound border were captured using an inverted microscope (Olympus BX51; Olympus Corp., Tokyo, Japan) after $24 \mathrm{~h}$ incubation at $37^{\circ} \mathrm{C}$ with $5 \% \mathrm{CO}_{2}$. The cell migration distances were quantified by subtracting the distance between the wound edges at $24 \mathrm{~h}$ from the distance measured at $0 \mathrm{~h}$. Each experiment was independently performed for at least three times.

Cell invasion assays. The $8 \mu \mathrm{m}$ plain (for migration) or Matrigelcoated (for invasion) (BD Biosciences, Franklin Lakes, NJ, USA) pore membrane and Transwell inserts (Corning Costar Corp., Corning, NY, USA) were placed in the wells of 24-well culture plates (Corning Costar Corp.) to assess the migrated or invasive ability of the cell sublines. Subsequently, EC9706 cells $\left(9 \times 10^{4}\right.$ per well) initially transfected with miR-34a mimic $(10 \mathrm{nM})$ or miR-control $(10 \mathrm{nM})$ were cultured for $24 \mathrm{~h}$. The ESCC cells were then harvested and re-suspended in $500 \mu \mathrm{l}$ serum-free DMEM medium. Accordingly, $150 \mu \mathrm{l}$ cell suspension was seeded into the upper chamber. Thereafter, $600 \mu \mathrm{l}$ DMEM containing 10\% FBS was added to the lower chamber to stimulate cell penetration. After $24 \mathrm{~h}$ incubation at $37^{\circ} \mathrm{C}$ with $5 \% \mathrm{CO}_{2}$, the DMEM was discarded and washed thrice with $1 \mathrm{X}$ PBS. The non-invasive cells that remained on top of the membrane were then manually removed with a cotton wool. The invading cells that adhered to the filter's undersurface were fixed using $4 \%$ paraformaldehyde (Solarbio, Beijing, China) for $30 \mathrm{~min}$ at $4^{\circ} \mathrm{C}$, dried under room temperature, and stained with $0.1 \%$ crystal violet for $20 \mathrm{~min}$. The Transwell inserts were thoroughly washed with water. The invaded cells were counted under a microscope in five randomly chosen fields. Representative images were then taken. Data are expressed as the number of invaded cells (means \pm standard deviation) normalized to the number of control cells that migrated. Each test was performed in triplicate.

Target gene prediction and luciferase reporter assay. The predicted miR-34a target genes and their target binding site regions were investigated using a bioinformatics tool (TargetScan, miRanda, RNA22 software) and a literature review. We analyzed the biological function and distribution on the tissue of the target genes. We then chose the migration- and invasion-related genes and their relationship with the ESCC. We found that MMP-2, MMP-9, and FNDC3B mRNA contained putative miR-34a target sites. The miR-34a target sequences in the MMP-9 coding region and the MMP-2 and FNDC3B 3'UTR region were amplified by PCR. These sequences were then inserted into multiple cloning sites of the pMIR-REPORT that contained a firefly luciferase reporter gene (Obio Technology, Shanghai, China). The mutant reporter vectors of the MMP-9 coding region and the MMP-2 and FNDC3B 3'-UTR regions that lacked the miR-34a binding sites were obtained through site-directed mutagenesis. All constructs were verified by DNA sequencing.

For the luciferase reporter assay, the EC9706 and 293T cells $\left(14 \times 10^{4}\right)$ were seeded into 24 -well plates the day before transfection to ensure $80 \%$ confluence at the time of transfection. Accordingly, $1 \mu \mathrm{g}$ of firefly luciferase reporter plasmid, including the wild-type or mutant coding regions of MMP-9, 3'UTR of MMP-2, and 3'UTR of FNDC3B, and $0.05 \mu \mathrm{g}$ of pRL-TK, which is a plasmid expressing the Renilla luciferase, were transfected into EC9706 and 293T cells cultured in 24-well plates together with $50 \mathrm{nM}$ miR-34a mimic or negative control and $100 \mathrm{nM}$ of miR-34a inhibitor or negative control using Lipofectamine 2000 (Invitrogen Life Technologies, Carlsbad, CA, USA). The cells were subjected to lysis $48 \mathrm{~h}$ post-transfection. The luciferase activities were determined using the dual luciferase reporter assay system (Promega) according to the manufacturer's instructions. The relative firefly luciferase activity (i.e., firefly luciferase activity/Renilla luciferase activity) for each construct was compared to the negative control. The luciferase activity was averaged in triplicate for each transfection.

Western blot analysis. The ESCC cells were transfected with miR-34a mimic or miR-34a inhibitor using the previously described method. The cells were washed three times with $1 \mathrm{X}$ PBS $48 \mathrm{~h}$ post-transfection and lysed with RIPA lysis buffer (Solarbio) in ice. The total proteins were extracted following standard protocol. Equal amounts of protein from whole cell lysates of each sample were separated on $10 \%$ sodium dodecyl sulfate polyacrylamide gel electrophoresis. These proteins were then transferred to a polyvinylidene difluoride membrane (Solarbio). The membranes were blocked in 5\% non-fat dried milk at room temperature for $2 \mathrm{~h}$. They were then incubated with primary antibodies at $4^{\circ} \mathrm{C}$ overnight and extensively washed. The membranes were further incubated with a corresponding secondary antibody at room temperature for $2 \mathrm{~h}$ after washing with $1 \mathrm{X}$ Tris-buffered saline buffer containing $0.1 \%$ Tween-20 six times $(5 \min \times 6)$. The primary antibodies against $\beta$-actin (diluted 1:1000; Zhongshan Golden Bridge Biotechnology, Beijing, China), MMP-9 (diluted 1:500; Abcam, Cambridge, MA, USA), MMP-2 (diluted 1:500; Cell Signaling Technology, Danvers, MA, USA), and FNDC3B (diluted 1:200; Santa Cruz Biotechnology, Santa Cruz, CA, USA) were employed. The secondary antibodies were used at 1:4000 to 1:5000 concentrations. The relative protein expression levels were quantified by the Gelpro analyzer software (GelPro32 4.0) using $\beta$-actin as the internal reference.

Statistical analysis. The statistical analyses were performed using SPSS 17.0 (SPSS Inc., Chicago, IL, USA). The experimental data are presented as mean \pm standard deviation based on the results of at least three repeats. The between-group comparisons were all based on Student's t-test. $\mathrm{P}<0.05$ was considered to indicate a statistically significant difference. 
A

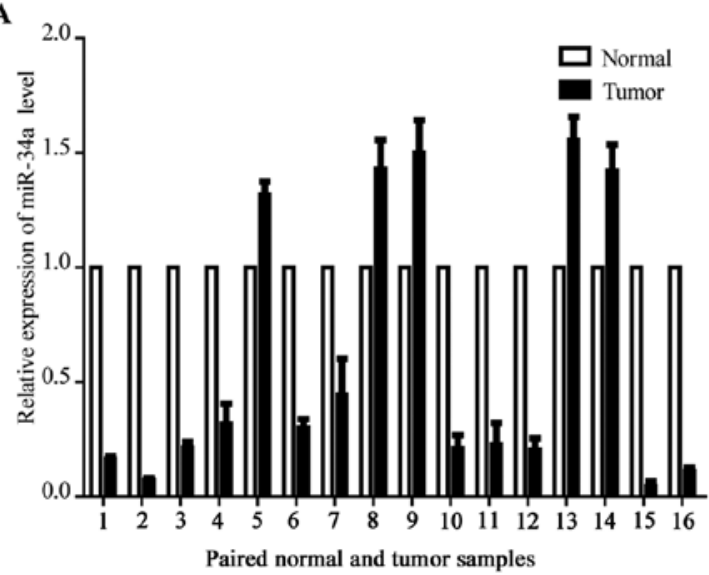

C

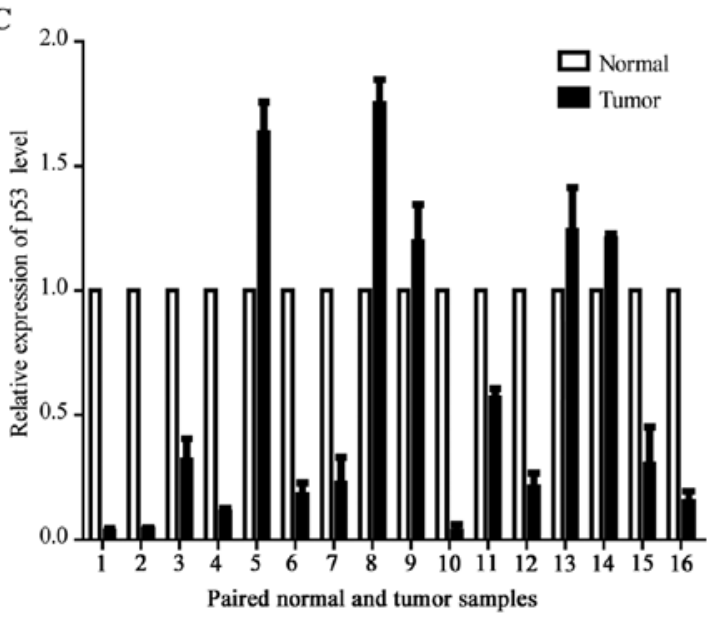

B

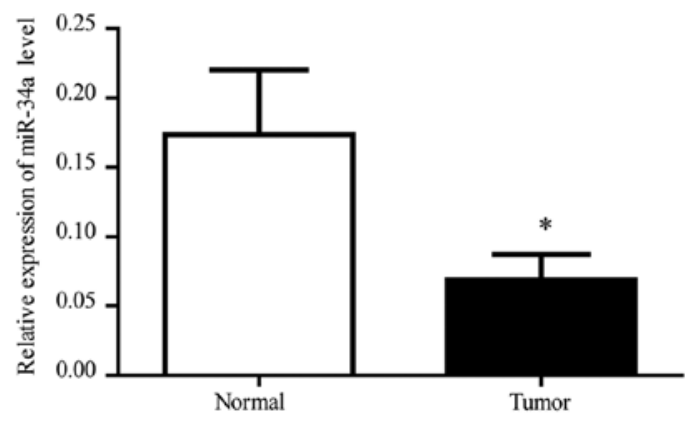

D

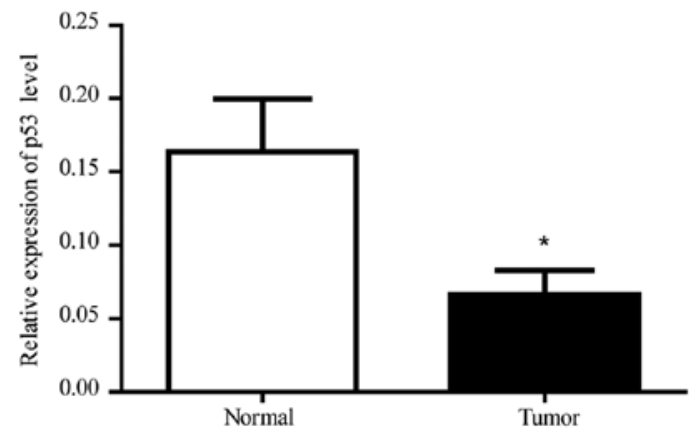

$\mathbf{E}$

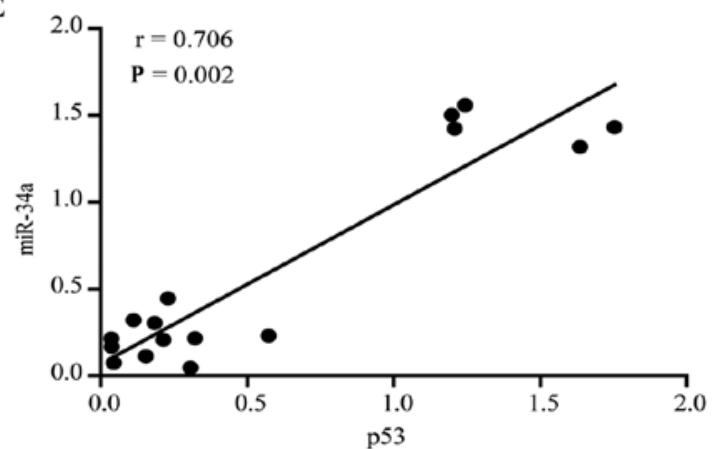

Figure 1. Decreased miR-34a and P53 expression in esophageal cancer. (A and C) Relative miR-34a and P53 levels in 16 ESCC specimens and matched normal

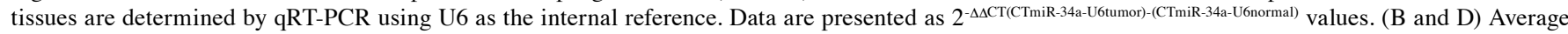
miR-34a and P53 expression in the ESCC and matched normal tissues. All values are normalized to U6 RNA levels. Data are presented as $2^{-\mathrm{ACT}(m i R-34 a-\mathrm{U} 6)}$ values ("P<0.05). (E) A potential positive correlation between p53 and miR-34a in ESCC $(\mathrm{P}<0.05)$.

\section{Results}

miR-34a expression is decreased in the ESCC. The miR-34a expression in the ESCC was confirmed by determining the miR-34a levels in the ESCC and normal esophageal tissues through qRT-PCR using U6 as the internal control. Fig. 1A shows that the miR-34a expression decreased in 11 of 16 (68.8\%) tumor samples. The average miR-34a expression also decreased in tumor tissues (Fig. 1B). In addition, the expression of p53 in ESCC tissues declined (Fig. 1C and D) with the miR34a expression level, the positive regulation expression between p53 and miR34a (Fig. 1E) indicate that miR34a may be a downstream target gene of p53 in ESCC similarly to other cancers.

miR-34a inhibits ESCC cell migration and invasion. The effects of miR-34a in the ESCC were investigated by transfecting the miR-34a mimics or the miR-34a inhibitor into the EC9706 and TE-1. The transfection efficiency was confirmed using qRT-PCR (Fig. 2). The cell migration assays were then performed within $48 \mathrm{~h}$ after miR-34a mimic transfection. The wound-healing assay showed that cell migration was significantly inhibited in the miR-34a mimic-transfected EC9706 cells compared with the negative control. A comparison to 
A

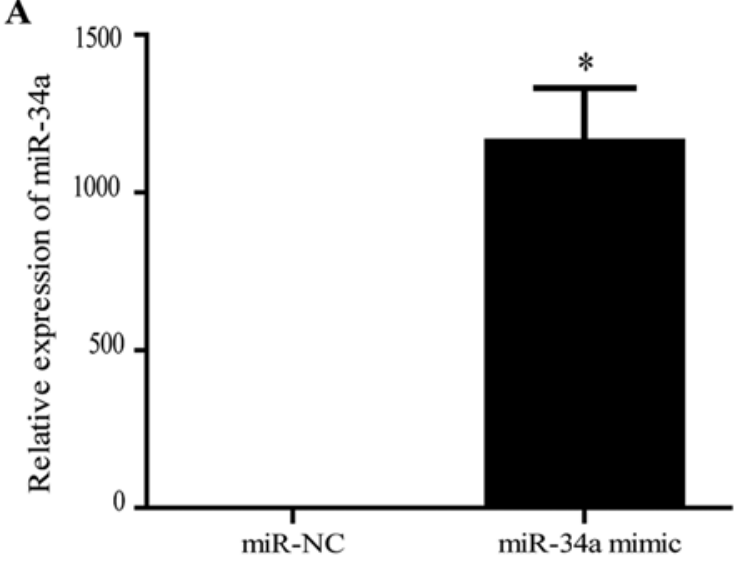

C

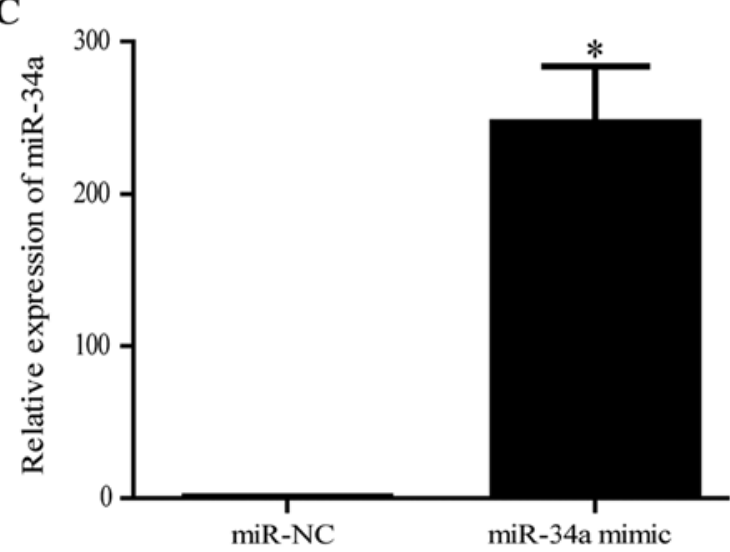

B

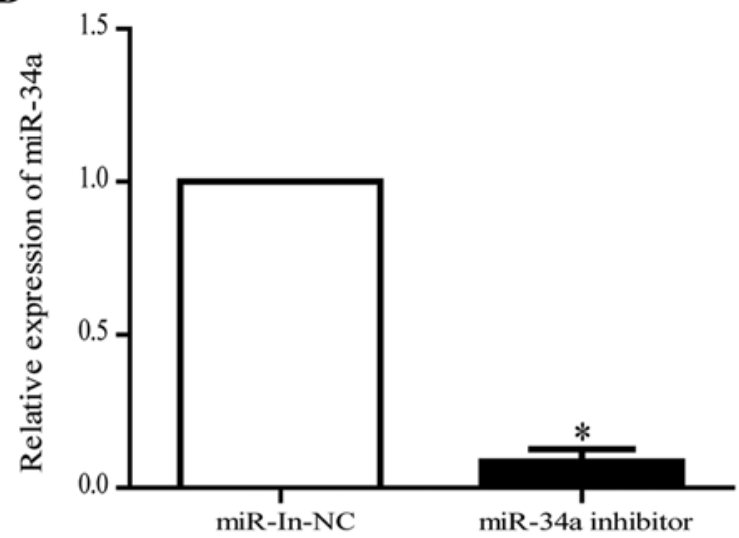

D

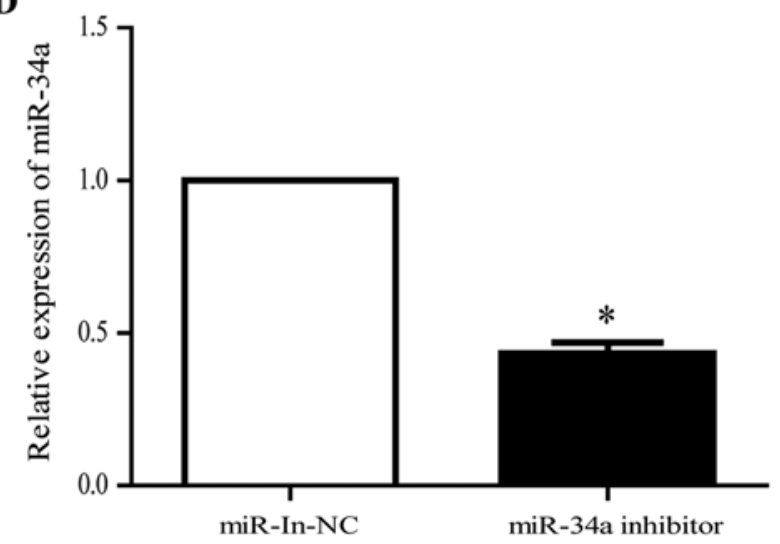

Figure 2. Transfection efficiency of miR-34a in esophageal cancer cells. (A and B) miR-34a expression in EC9706 cells was determined by qRT-PCR after transfecting miR-34a mimic, inhibitor, or negative control $\left({ }^{*} \mathrm{P}<0.05\right)$. ( $\mathrm{C}$ and $\left.\mathrm{D}\right) \mathrm{miR}-34 \mathrm{a}$ expression in TE-1 cells was determined by qRT-PCR after transfecting miR-34a mimic, inhibitor, or negative control ( $\left.{ }^{*} \mathrm{P}<0.05\right)$. NC, normal control; In, inhibitor.

the negative control shows that the inhibited miR-34a expression significantly promoted EC9706 cell migration (Fig. 3A). Similarly, cell migration was significantly inhibited in the miR-34a mimic-transfected TE-1 cells. miR-34a inhibition also promoted TE-1 cell migration (Fig. 3B). We conducted Transwell migration and invasion assays. Consequently, the results demonstrated that EC9706 cell migration and invasion were inhibited by the miR-34a overexpression. In contrast, the miR-34a inhibition promoted EC9706 cell migration and invasion (Fig. 3C and D). These results suggested that miR-34a could inhibit ESCC cell migration and invasion, and inhibiting the miR-34a expression can increase ESCC cell migration and invasion.

miR-34a directly targets and suppresses MMP-2/MMP-9/ $F N D C 3 B$ in ESCC cells. The prediction results obtained using the bioinformatics tool and the literature review indicated that the human miR-34a may target the MMP-9 coding region and the MMP-2 and FNDC3B 3'-UTR regions. Fig. 4A, C and E) showed the miR-34a putative binding sites and corresponding mutant sites of MMP-9, MMP-2, and FNDC3B. We constructed luciferase reporter plasmids containing putative sequences for MMP-2, MMP-9, and FNDC3B or their corresponding mutant sequences as controls to further confirm that miR-34a directly targeted MMP-2, MMP-9, and FNDC3B. At 48 h post-trans- fection, the luciferase activity of the reporter containing the miR-34a-targeted wild-type sequences of MMP-9 was significantly suppressed in the 293T cells (Fig. 4B) and EC9706 cells (data not shown) with miR-34a overexpression but not their corresponding mutant sequences. Similarly, the luciferase activity of the reporter containing the miR-34a-targeted wildtype sequences of MMP-2 and FNDC3B was significantly suppressed in the 293T cells (Fig. 4D and F) and EC9706 cells (data not shown) with miR-34a overexpression but not their corresponding mutant sequences.

On the contrary, the luciferase activity of the reporter containing the miR-34a-targeted wild-type sequences of MMP-2, MMP-9, and FNDC3B increased in the miR-34a inhibitor-transfected 293T cells (Fig. 4B, D and F) and EC9706 cells (data not shown) but not their corresponding mutant sequences. The influence of miR-34a on MMP-2, MMP-9, and FNDC3B expression levels was further confirmed by measuring the MMP-2, MMP-9, and FNDC3B levels in the EC9706 cells and TE-1cells with miR-34a overexpression or miR-34a inhibition. The result showed that MMP-9, MMP-2, and FNDC3B presented an inverse expression trend to miR-34a in the EC9706 cells (Fig. 5A-C) and TE-1 cells (Fig. 5D-F). On the one hand, western blot analysis demonstrated that the miR-34a overexpression decreased the protein levels of MMP-2, MMP-9, and FNDC3B in the EC9706 cells (Fig. 6A) 
A

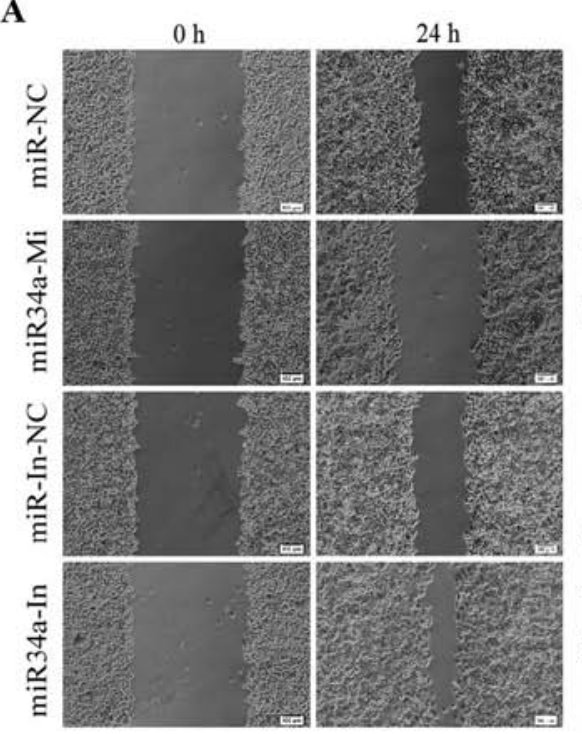

C

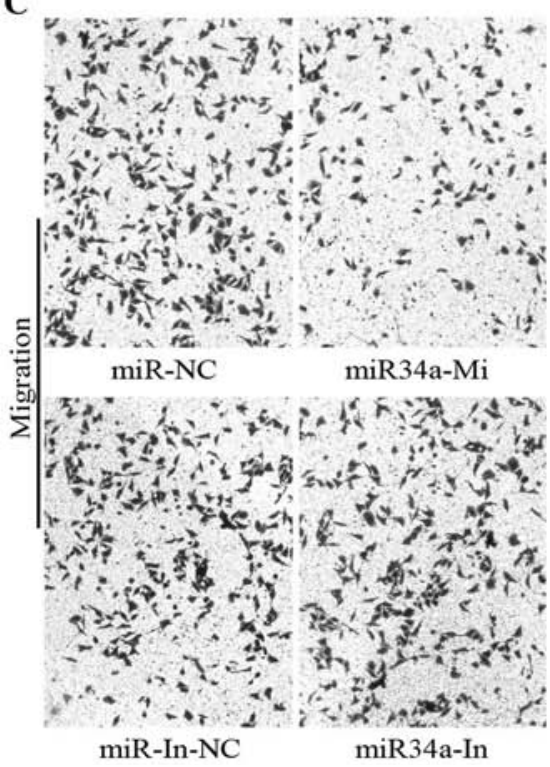

B
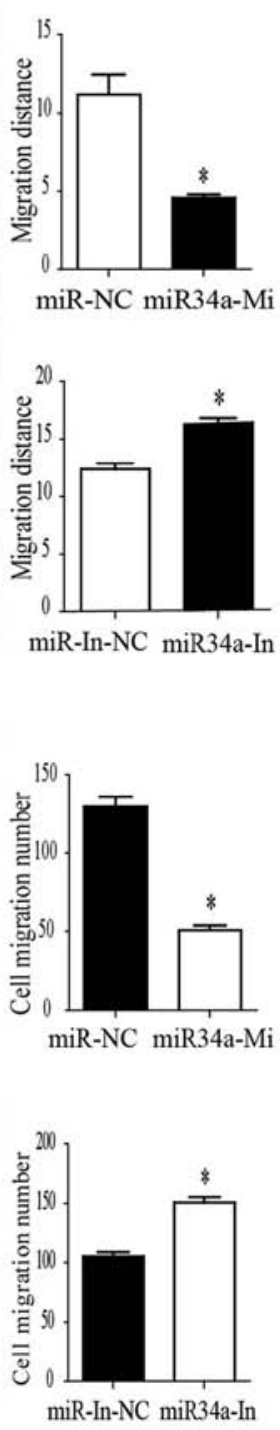

D
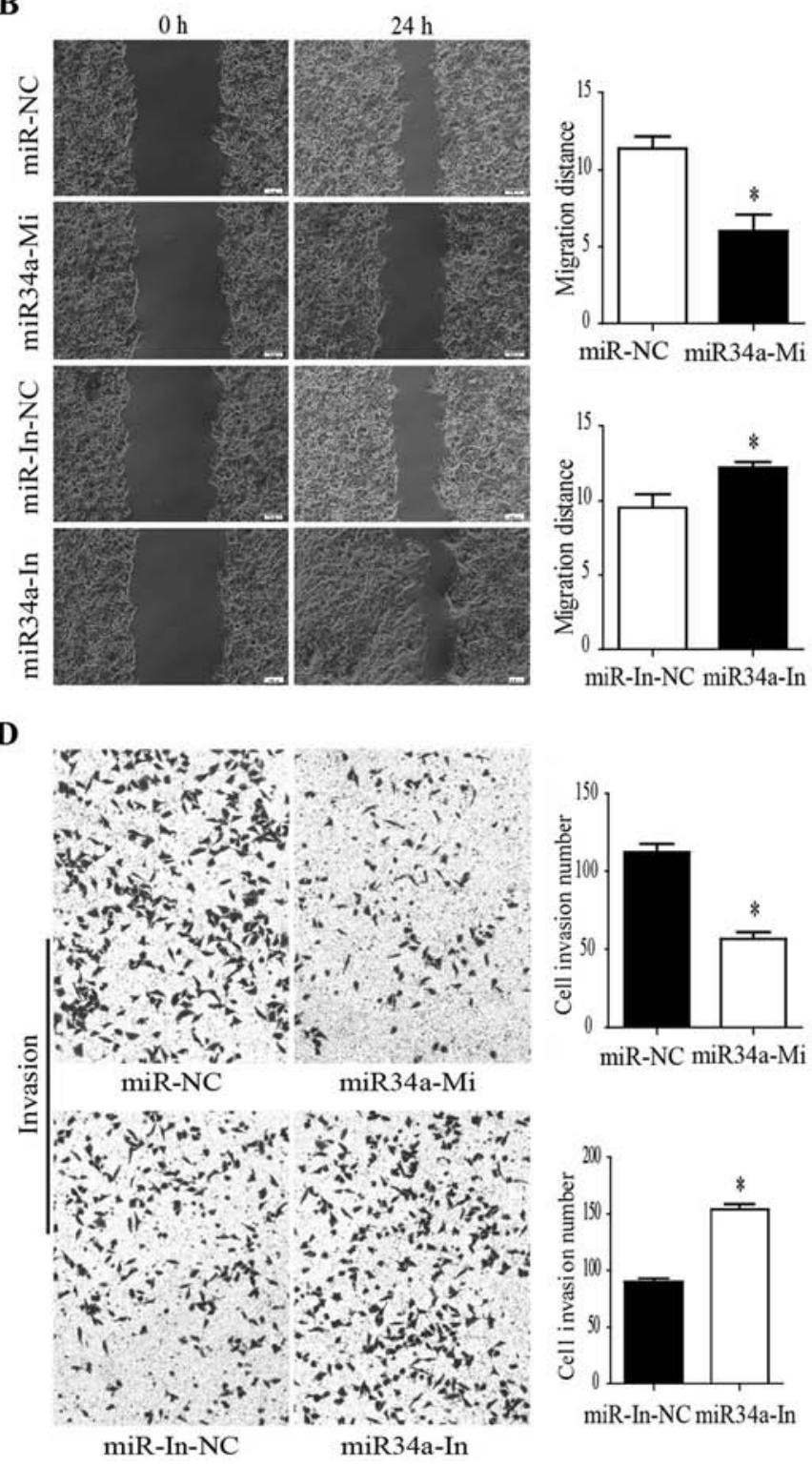
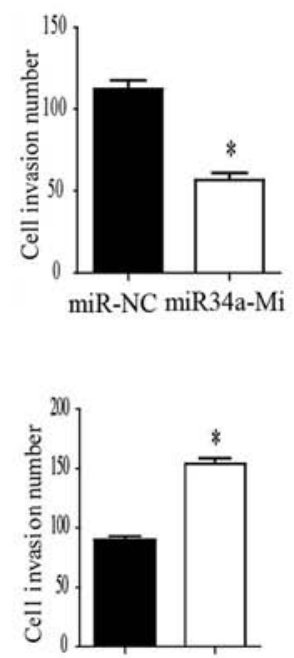

miR-In-NC miR34a-In

Figure 3. miR-34a inhibits ESCC cell migration and invasion. (A and B) EC9706 and TE-1 cells were transfected with miR-34a mimic, inhibitor, and negative controls and were assessed for migration by wound-healing assay at $0 \mathrm{~h}$ and $24 \mathrm{~h}$. ( $\left.{ }^{*} \mathrm{P}<0.05\right)$. (C and D) Effects of miR-34a mimic or miR-34a inhibitor on EC9706 cell migration and invasion obtained using the Transwell assay ( $\left.{ }^{\mathrm{P}}<0.05\right)$. NC, normal control; In, inhibitor; Mi, mimic.

and TE-1 cells (Fig. 6B). On the other hand, the miR-34a inhibitor transfection increased the protein levels of MMP-2, MMP-9, and FNDC3B in the EC9706 cells (Fig. 6A) and TE-1 cells (Fig. 6B). These data demonstrated that miR-34a directly binds to MMP-2/MMP-9/FNDC3B and represses the MMP-2/ MMP-9/FNDC3B translation in ESCC cells.

\section{Discussion}

ESCC is the leading cause of mortality in digestive tract malignancies, with a poor five-year overall survival rate (2-4). Therefore, a better understanding of the mechanisms involved in ESCC progression is urgent. miRNAs have demonstrated far-reaching effects on cellular biology and cancer development $(40,41)$. A number of studies have reported a relatively low miR-34a expression level in various cancer types and cancer cell lines, including ESCC (12,21-26,39,42,43).
The present study found that the miR-34a as well as p53 expression was significantly reduced in human esophageal tumor tissues compared to adjacent normal tissues. It may be a potential positive control correlation between p53 and miR-34a in ESCC as previously reported in other cancers. Epigenetic mechanisms, including methylation and histone modification, chromosome deficiency, and transcriptional regulation, can influence the miRNA expression (44). Furthermore, the abnormal miR-34a expression is reported in multiple cancers (e.g., breast, lung, colon, and bladder cancers, and pancreatic carcinoma) due to aberrant CpG methylation of its promoter $(45,46)$. A study found that the miR-34a promoter is more frequently methylated in the ESCC than in controls. Accordingly, the miR-34a expression decreases in patients with a high level of methylation compared to that in normal tissues (42). It indicates that the mechanisms of miR-34a repression may be aberrant from the $\mathrm{CpG}$ methylation of its promoter in ESCC. 


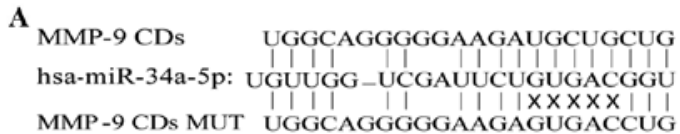

B
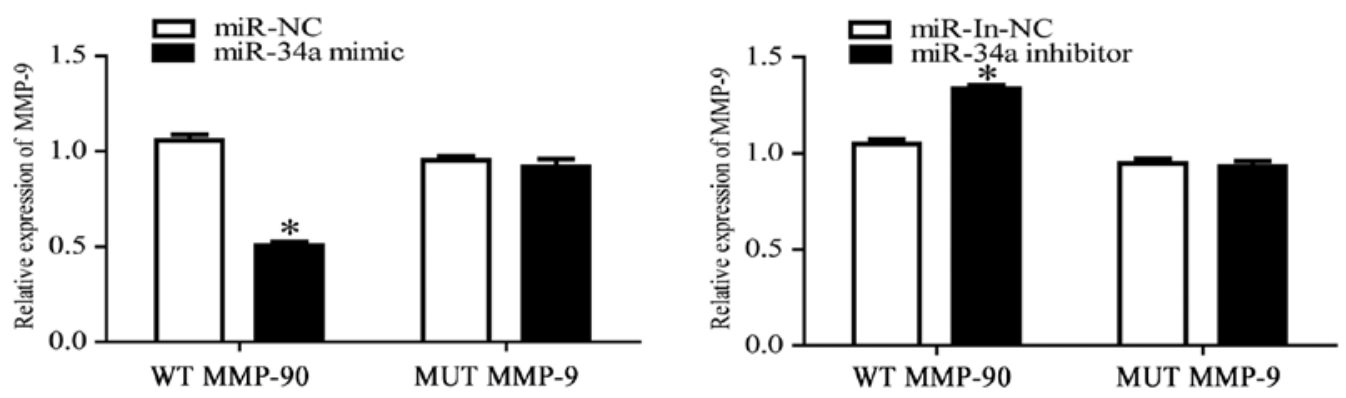

$\mathrm{C}_{\mathrm{M}}$

$\begin{array}{lr}\text { MMP-2 3'-UTR } & \text { CACUGCC U } \\ \text { I I I 1 I I } \\ \text { hsa-miR-34a-5p:UGUUGGUCGAUUCU GUGACGG U } \\ \text { : XXXXX } \\ \text { MMP-2 3'-UTR MUT } & \text { UUAAAAAA A }\end{array}$

D
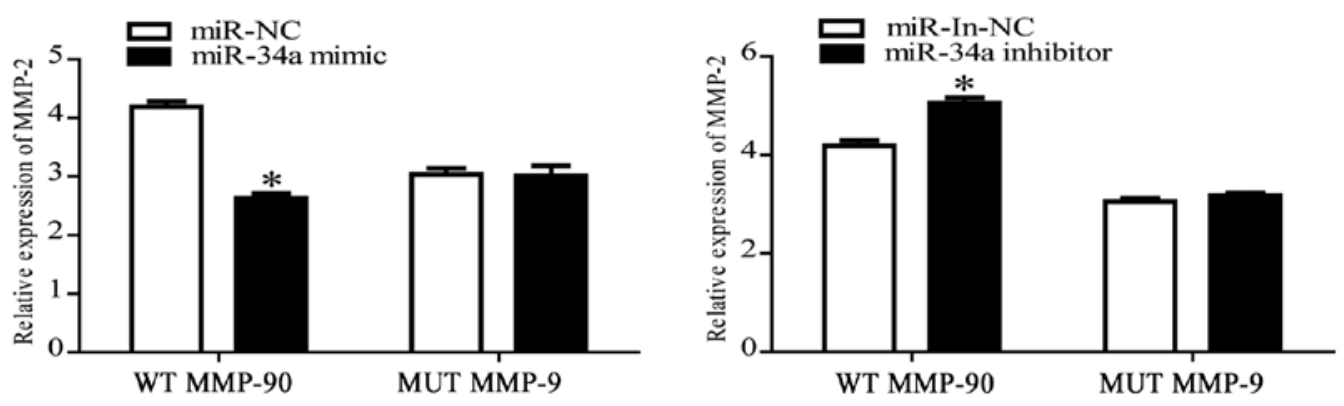

E

E

AACUGCC A

hsa-miR-34a-5p:UGUUGGUCGAUUCUG UGACGG U

FNDC3B $3^{2}$ UTR MUT

C ĠUACGU U
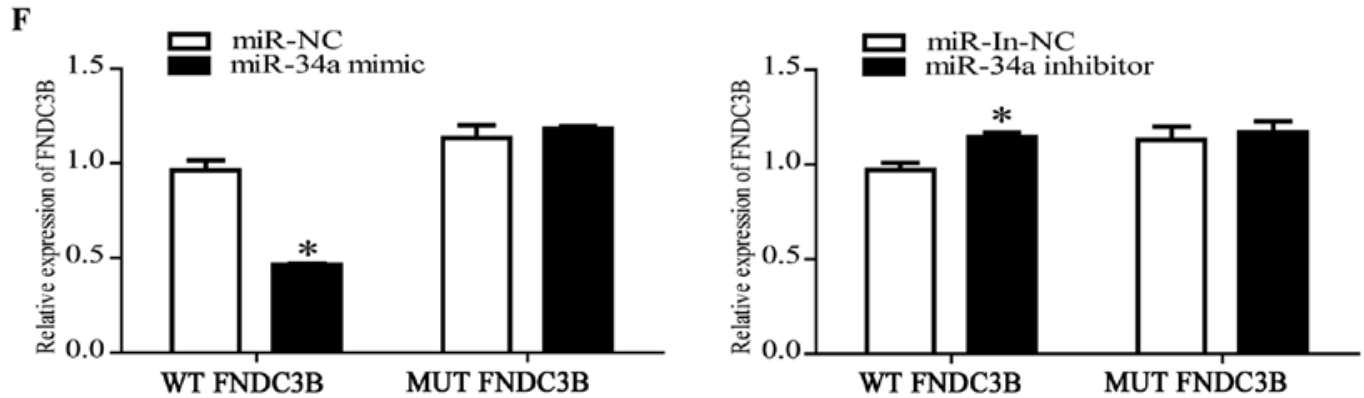

Figure 4. miR-34a suppresses luciferase activity of the reporter containing the miR-34a-targeted wild-type sequences of MMP-2, MMP-9, and FNDC3B. (A) Diagrams show the miR-34a putative binding sites and corresponding mutant sites of MMP-9. (B) Relative luciferase activity was determined after wild-type or mutant MMP-9 CDs reporter plasmids were co-transfected with miR-34a mimic or inhibitor in 293T cells. (C) The MMP-2 3'UTR regions containing the wild-type or mutant binding site for miR-34a are shown. (D) Relative luciferase activity was determined after wild-type or mutant MMP-2 3'UTR reporter plasmids were co-transfected with miR-34a mimic or inhibitor in $293 \mathrm{~T}$ cells. (E) The FNDC3B 3'UTR regions containing the wild-type or mutant binding site for miR-34a are shown. (F) Relative luciferase activity was determined after wild-type or mutant FNDC3B 3'UTR reporter plasmids were co-transfected with miR-34a mimic or inhibitor in $293 \mathrm{~T}$ cells. Data were normalized to the luciferase activity after transfection with miR-NC or miR-In-NC. ( $\mathrm{P}<0.05$ ). NC, normal control; In, inhibitor; WT, wild-type; MUT, mutant type.

Studies have found that miR-34a overexpression can suppress cell proliferation, migration, invasion, and EMT (22-24,27-31,43). Furthermore, miR-34a has significant relationships with node metastases, clinical stage, and patient mortality in tongue squamous cell carcinoma (12) and
ESCC (43). This finding indicates that miR-34a has a crucial role in tumor development, progression, and prognosis. We observed that miR-34a inhibits ESCC cell migration and invasion, which is consistent with previous results (39). Cell migration and invasion are normal events in cancer processes 
A

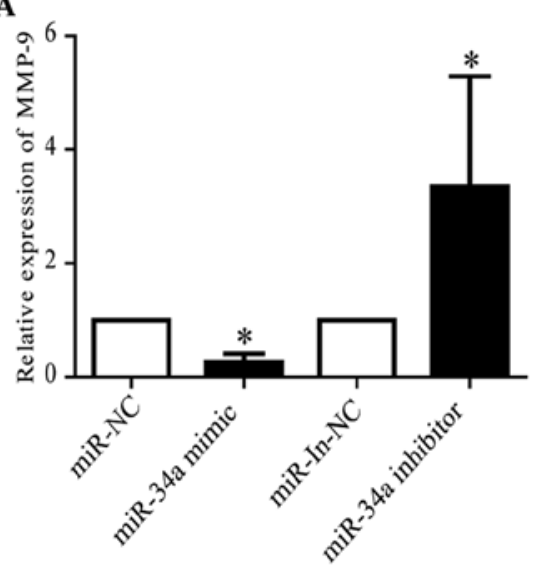

D

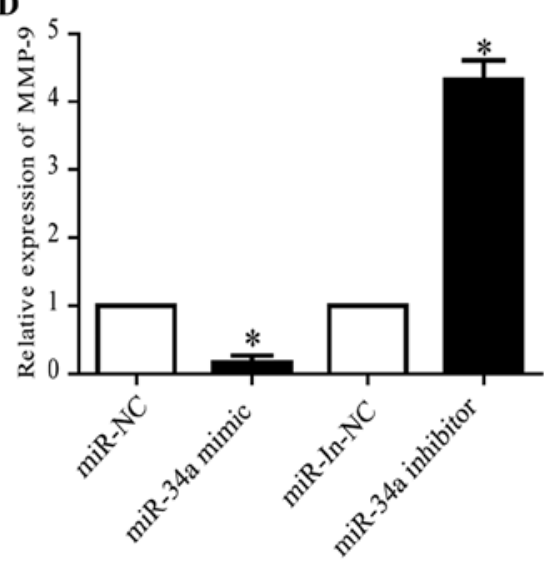

B

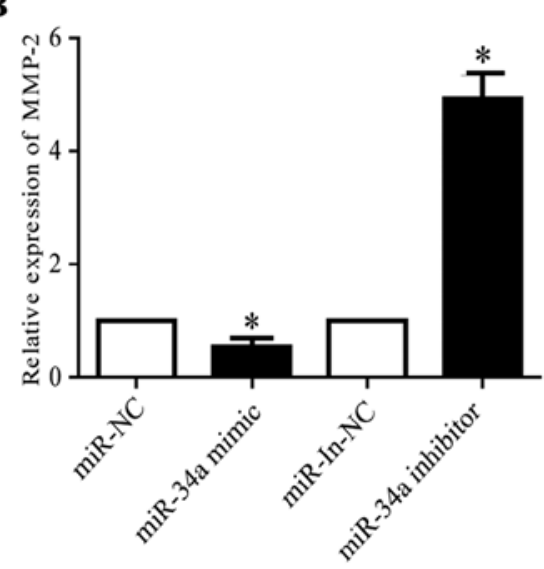

E

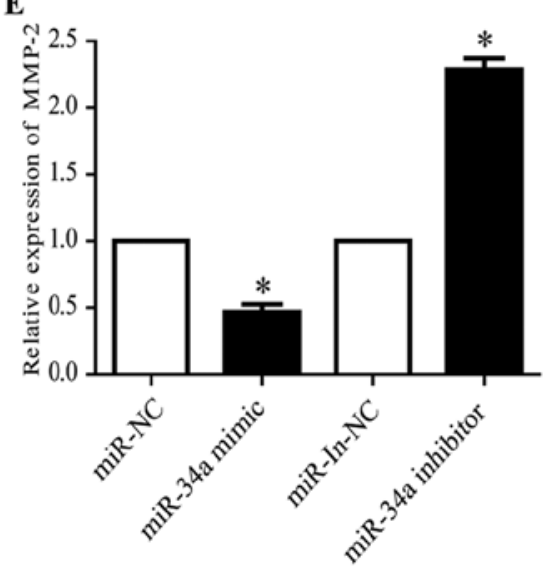

C
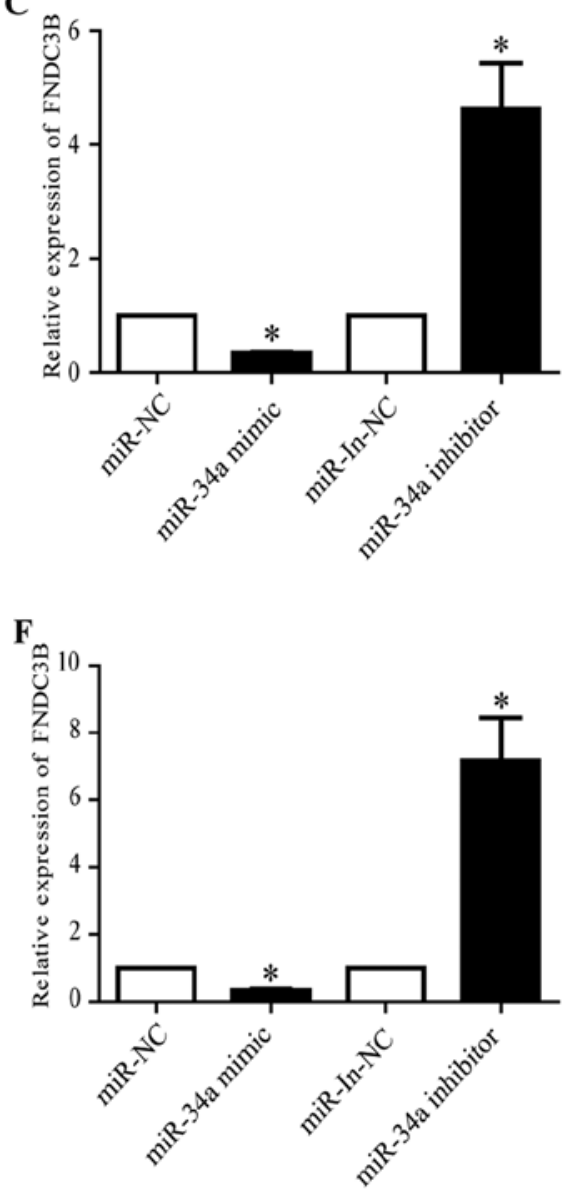

Figure 5. miR-34a overexpression decreases the MMP-2, MMP-9, and FNDC3B mRNA levels. (A-C) qRT-PCR detection of MMP-9, MMP-2, and FNDC3B mRNA expression in EC9706 cells transfected with miR-34a mimic or inhibitor. miR-34a overexpression decreases the MMP-2, MMP-9, and FNDC3B mRNA levels, whereas miR-34a inhibition increases them ( $\mathrm{P}<0.05$ ). (D-F) qRT-PCR detection of MMP-9, MMP-2, and FNDC3B mRNA expression in TE-1 cells transfected with miR-34a mimic or inhibitor. miR-34a overexpression decreases the MMP-2, MMP-9, and FNDC3B mRNA levels, whereas miR-34a inhibition increases them $\left({ }^{*} \mathrm{P}<0.05\right)$. NC, normal control; In, inhibitor.

and are two important elements that lead to metastases. Metastasis is a major cause of death in patients with esophageal cancer (6). miR-34a has been reported to suppress cell migration and invasion by targeting various oncogenes $(22,24,25,30)$.

Previous studies reveal that miR-34a can inhibit ESCC cell migration and invasion by targeting YY-1. However, miR-34a might still directly modulate other genes simultaneously inhibiting ESCC cell migration and invasion because of the complex regulative network of miRNAs. We have found that MMP-2 and MMP-9 contain putative miR-34a target sites using a bioinformatics tools and a literature review. The MMP family, especially MMP-2 and MMP-9 known as gelatinases, is involved in cancer migration and invasion by degrading type-IV collagen, which is the major component of the basement membrane. MMP-2 and MMP-9 play vital roles in the early stages of tumor invasion. They are secreted during tumor growth, and can affect the surrounding microenvironment, thereby causing dynamic changes in the tumor bio-behavior (47).

MMP-2 and MMP-9 are reportedly overexpressed in ESCC tissues compared to that in the paired normal esophageal tissues. They are also related to tumor invasion and metastasis in the ESCC $(48,49)$. The luciferase reporter assays in this study reveal that miR-34a could directly interact with MMP-2 and MMP-9. Both mRNA and protein levels of MMP-2 and MMP-9 significantly decrease when miR-34a is overexpressed in ESCC cells. This finding is consistent with a report of an indirect negative correlation of miR-34a with MMP-2 and MMP-9 in ESCC (39). However, our results show that miR-34a directly targets MMP-2 or MMP-9. This finding seems to be different from the results of a previous report (39), where miR-34a indirectly downregulates MMP-2 or MMP-9 suppressing YY-1 in the ESCC. The current study also confirms that miR-34a directly targets MMP-9 in tongue squamous cell carcinoma (12) and Fra-1 in colon cancer (22). miR-34a may downregulate mRNA expression through direct and indirect regulatory mechanisms.

We also found that FNDC3B is the most likely direct target gene of miR-34a using a bioinformatics software and a literature review. FNDC3B is located at 3q26.31 and covers a large area $(360 \mathrm{~kb})$. FNDC3B is a member of the fibronectin family (50) with biological functions that remain largely unclear. The gene, which was initially discovered with another name (i.e., factor for adipocyte differentiation 104), is upregulated in the early stages of adipocyte differentiation. This upregulation indicates its potential role as a positive regulator 
A
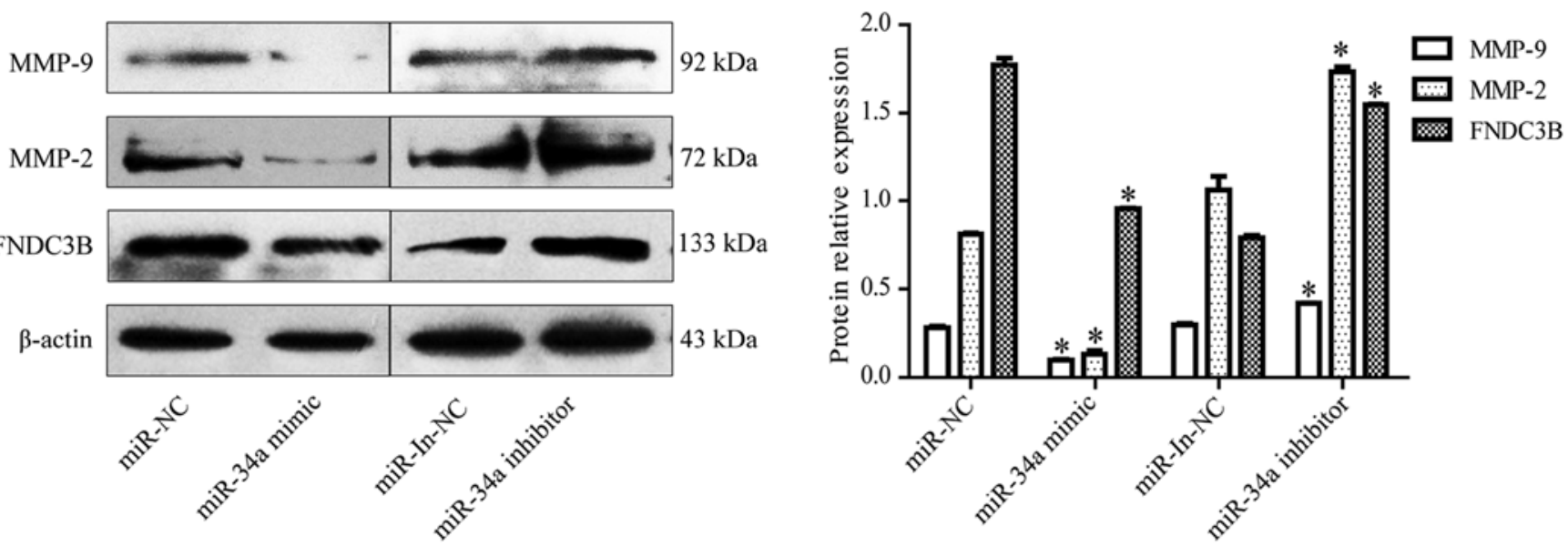

B
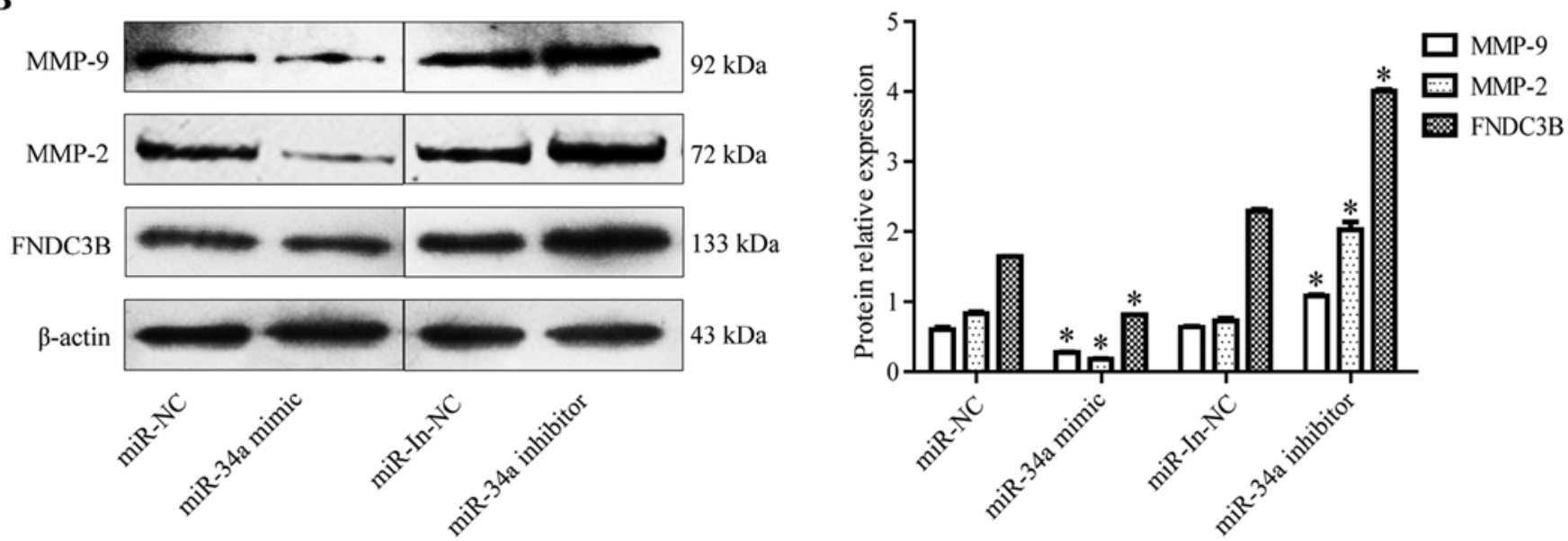

Figure 6. miR-34a overexpression decreases the MMP-2, MMP-9, and FNDC3B protein levels. (A) The MMP-9, MMP-2, and FNDC3B protein levels in the EC9706 cells transfected with miR-34a mimic or miR-34a inhibitor were detected by western blotting. miR-34a overexpression decreases the MMP-2, MMP-9, and FNDC3B protein levels, whereas miR-34a inhibition increases them ("P<0.05). (B) Western blot detection of MMP-9, MMP-2, and FNDC3B mRNA expression in TE-1 cells transfected with miR-34a mimic or inhibitor. miR-34a overexpression decreases the MMP-2, MMP-9, and FNDC3B protein levels, whereas miR-34a inhibition increases them $\left({ }^{*} \mathrm{P}<0.05\right)$. NC, normal control; In, inhibitor.

of adipogenesis $(51,52)$. However, FNDC3B has been recently identified as an important oncogenic driver gene of the $3 \mathrm{q}$ amplicon, thereby adding to the growing list of oncogenic drivers within this amplified region (53).

Previous studies have reported that miR-143-targeted the oncogene FNDC3B, regulating hepatocarcinoma metastasis (54). Furthermore, FNDC3B amplification could increase cell proliferation and promote tumorigenesis of hepatocellular carcinoma (50). The amplification and overexpression of FNDC3B are found in over $20 \%$ of cancers including ESCC $(50,53,55)$. However, the role of FNDC3B in ESCC is presently still unconfirmed. Studies have found that the FNDC3B expression is significantly altered in ESCC and targeted by most miRNAs (56). In addition, FNDC3B overexpression induces EMT and activates several cancer pathways, including TGF $\beta 1$ signaling, which contributes to cancer metastasis (53). miR-34a acts as a suppressor that regulates TGF $\beta 1$ signaling by targeting PDGFRA in glioblastoma (57) and Smad4 inhibits EMT in extrahepatic cholangiocarcinoma (58). The TGF $\beta 1$ signaling is an activity in ESCC that could induce EMT and contribute to ESCC metastasis (59). Therefore, whether miR-34a has a connection with the TGF $\beta 1$ signaling by regulating FNDC3B in ESCC needs to be determined. We have performed luciferase reporter assays to confirm that miR-34a could directly interact with FNDC3B. The results revealed that miR-34a could suppress the luciferase activity of the reporter containing the miR-34a-targeted wild-type sequences of FNDC3B. Both mRNA and protein levels of FNDC3B also significantly decrease when miR-34a is overexpressed in ESCC cells. In view of these results, FNDC3B is a direct target gene of miR-34a and may be important in the regulatory network. FNDC3B may also be involved in the progression of ESCC. We detected that FNDC3B could promote the ESCC cell invasion and migration (data not shown), combining this result with previous reports $(53,59)$, we propose a hypothesis that miR-34a inhibits ESCC cell migration and invasion by targeting FNDC3B and reduces EMT by inhibiting the activity of the TGF $\beta 1$ signaling pathway. This hypothesis needs further research.

Previous studies have confirmed that miR-34a is a downstream target of p53 (60). However, few studies have 
reported the downstream targets of miR-34a in ESCC. Only one study found that miR-34a could directly target YY-1 in ESCC (39). In the present study, we found that miR-34a could directly target MMP-2, MMP-9, and FNDC3B in ESCC. miR-34a can directly and simultaneously modulate multiple genes in ESCC because of the complex regulative network of miRNAs.

This study confirmed that miR-34a expression significantly decreased in ESCC tissues and could inhibit the ESCC cell line migration and invasion. Accordingly, MMP-2, MMP-9, and FNDC3B are the genes directly targeted by miR-34a. miR-34a may have a therapeutic value in ESCC treatment. Therefore, further studies on the anticancer mechanisms of miR-34a may contribute to the development of new therapeutic strategies for ESCC.

\section{Acknowledgements}

This study was supported in part by the National Natural Science Foundation of China (grant nos. 81260301, 81560399, 81160301, 81360358, and 81460362). The doctoral grant from the Xinjiang Production and Construction Corps (grant no. 2014BB019) and the high-level talent project of Shihezi University (no. RCZX201533) are also acknowledged. We thank the Biochemical Laboratory of the Shihezi University School of Medicine for raising the 293T in this study. The authors would also like to express their sincere thanks to ShineWrite.com, the professional editing company, for editing and modifying the English in the manuscript.

\section{References}

1. Chen W, Zheng R, Zeng H and Zhang S: The updated incidences and mortalities of major cancers in China, 2011. Chin J Cancer 34: 502-507, 2015

2. Gamliel Zand Krasna MJ: Multimodality treatment of esophageal cancer. Surg Clin North Am 85: 621-630, 2005.

3. Lee KH, Goan YG, Hsiao M, Lee CH, Jian SH, Lin JT, Chen YL and Lu PJ: MicroRNA-373 (miR-373) post-transcriptionally regulates large tumor suppressor, homolog 2 (LATS2) and stimulates proliferation in human esophageal cancer. Exp Cell Res 315: 2529-2538, 2009.

4. Li H, Zheng D, Zhang B, Liu L, Ou J, Chen W, Xiong S, Gu Y and Yang J: Mir-208 promotes cell proliferation by repressing SOX6 expression in human esophageal squamous cell carcinoma. J Transl Med 12: 196, 2014.

5. Wang X, Tian X, Liu F, Zhao Y, Sun M, Chen D, Lu C, Wang Z, Shi X, Zhang Q, et al: Detection of HPV DNA in esophageal cancer specimens from different regions and ethnic groups: A descriptive study. BMC Cancer 10: 19, 2010.

6. Jemal A, Siegel R, Ward E, Hao Y, Xu J and Thun MJ: Cancer statistics, 2009. CA Cancer J Clin 59: 225-249, 2009.

7. Mizushima T, Nakagawa H, Kamberov YG, Wilder EL, Klein PS and Rustgi AK: Wnt-1 but not epidermal growth factor induces beta-catenin/T-cell factor-dependent transcription in esophageal cancer cells. Cancer Res 62: 277-282, 2002.

8. Yang L, Leung AC, Ko JM, Lo PH, Tang JC, Srivastava G, Oshimura M, Stanbridge EJ, Daigo Y, Nakamura Y, et al: Tumor suppressive role of a $2.4 \mathrm{Mb} 9 \mathrm{q} 33-\mathrm{q} 34$ critical region and DEC1 in esophageal squamous cell carcinoma. Oncogene 24: 697-705, 2005.

9. Bartel DP: MicroRNAs: Genomics, biogenesis, mechanism, and function. Cell 116: 281-297, 2004.

10. Cimmino A, Calin GA, Fabbri M, Iorio MV, Ferracin M, Shimizu M, Wojcik SE, Aqeilan RI, Zupo S, Dono M, et al: miR-15 and miR-16 induce apoptosis by targeting BCL2. Proc Natl Acad Sci USA 102: 13944-13949, 2005.

11. Bartel DP: MicroRNAs: target recognition and regulatory functions. Cell 136: 215-233, 2009.
12. Jia LF, Wei SB, Mitchelson K, Gao Y, Zheng YF, Meng Z, Gan YH and Yu GY: miR-34a inhibits migration and invasion of tongue squamous cell carcinoma via targeting MMP9 and MMP14. PLoS One 9: e108435, 2014.

13. Bushati N and Cohen SM: microRNA functions. Annu Rev Cell Dev Biol 23: 175-205, 2007.

14. Phatak P, Byrnes KA, Mansour D, Liu L, Cao S, Li R, Rao JN, Turner DJ, Wang JY and Donahue JM: Overexpression of miR214-3p in esophageal squamous cancer cells enhances sensitivity to cisplatin by targeting survivin directly and indirectly through CUG-BP1. Oncogene 35: 2087-2097, 2016.

15. Duursma AM, Kedde M, Schrier M, le Sage C and Agami R: miR-148 targets human DNMT3b protein coding region. RNA 14: 872-877, 2008.

16. Calin GA and Croce CM: MicroRNA signatures in human cancers. Nat Rev Cancer 6: 857-866, 2006.

17. Blower PE, Chung JH, Verducci JS, Lin S, Park JK, Dai Z, Liu CG, Schmittgen TD, Reinhold WC, Croce CM, et al: MicroRNAs modulate the chemosensitivity of tumor cells. Mol Cancer Ther 7: 1-9, 2008.

18. Zhang B, Pan X, Cobb GP and Anderson TA: microRNAs as oncogenes and tumor suppressors. Dev Biol 302: 1-12, 2007.

19. Ambros V: The functions of animal microRNAs. Nature 431: 350-355, 2004.

20. He L, He X, Lim LP, de Stanchina E, Xuan Z, Liang Y, Xue W, Zender L, Magnus J, Ridzon D, et al: A microRNA component of the p53 tumour suppressor network. Nature 447: 1130-1134, 2007.

21. Gallardo E, Navarro A, Viñolas N, Marrades RM, Diaz T, Gel B, Quera A, Bandres E, Garcia-Foncillas J, Ramirez J, et al: $\mathrm{miR}-34 \mathrm{a}$ as a prognostic marker of relapse in surgically resected non-small-cell lung cancer. Carcinogenesis 30: 1903-1909, 2009.

22. Wu J, Wu G, Lv L, Ren YF, Zhang XJ, Xue YF, Li G, Lu X, Sun Z and Tang KF: MicroRNA-34a inhibits migration and invasion of colon cancer cells via targeting to Fra-1. Carcinogenesis 33: 519-528, 2012.

23. Nalls D, Tang SN, Rodova M, Srivastava RK and Shankar S: Targeting epigenetic regulation of miR-34a for treatment of pancreatic cancer by inhibition of pancreatic cancer stem cells. PLoS One 6: e24099, 2011.

24. Sun H, Tian J, Xian W, Xie T and Yang X: miR-34a inhibits proliferation and invasion of bladder cancer cells by targeting orphan nuclear receptor HNF4G. Dis Markers 2015: 879254, 2015.

25. Liu C, Kelnar K, Liu B, Chen X, Calhoun-Davis T, Li H, Patrawala L, Yan H, Jeter C, Honorio S, et al: The microRNA miR-34a inhibits prostate cancer stem cells and metastasis by directly repressing CD44. Nat Med 17: 211-215, 2011.

26. Corney DC, Hwang CI, Matoso A, Vogt M, Flesken-Nikitin A, Godwin AK, Kamat AA, Sood AK, Ellenson LH, Hermeking H, et al: Frequent downregulation of miR-34 family in human ovarian cancers. Clin Cancer Res 16: 1119-1128, 2010.

27. Sun F, Fu H, Liu Q, Tie Y, Zhu J, Xing R, Sun Z and Zheng X: Downregulation of CCND1 and CDK6 by miR-34a induces cell cycle arrest. FEBS Lett 582: 1564-1568, 2008.

28. Wei JS, Song YK, Durinck S, Chen QR, Cheuk AT, Tsang P, Zhang Q, Thiele CJ, Slack A, Shohet J, et al: The MYCN oncogene is a direct target of miR-34a. Oncogene 27: 5204-5213, 2008 .

29. Yamakuchi M,Ferlito M and Lowenstein CJ: miR-34a repression of SIRT1 regulates apoptosis. Proc Natl Acad Sci USA 105: 13421-13426, 2008.

30. Yan D, Zhou X, Chen X, Hu DN, Dong XD, Wang J, Lu F, Tu L and Qu J: MicroRNA-34a inhibits uveal melanoma cell proliferation and migration through downregulation of c-Met. Invest Ophthalmol Vis Sci 50: 1559-1565, 2009.

31. Kang J, Kim E, Kim W, Seong KM, Youn H, Kim JW, Kim J and Youn B: Rhamnetin and cirsiliol induce radiosensitization and inhibition of epithelial-mesenchymal transition (EMT) by miR34a-mediated suppression of Notch-1 expression in non-small cell lung cancer cell lines. J Biol Chem 288: 27343-27357, 2013.

32. Guessous F, Zhang Y, Kofman A, Catania A, Li Y, Schiff D, Purow B and Abounader R: microRNA-34a is tumor suppressive in brain tumors and glioma stem cells. Cell Cycle 9: 1031-1036, 2010.

33. Kang L, Mao J, Tao Y, Song B, Ma W, Lu Y, Zhao L, Li J, Yang B and Li L: MicroRNA-34a suppresses the breast cancer stem cell-like characteristics by downregulating Notch1 pathway. Cancer Sci 106: 700-708, 2015. 
34. Bu P, Chen KY, Chen JH, Wang L, Walters J, Shin YJ, Goerger JP, Sun J, Witherspoon M, Rakhilin N, et al: A microRNA miR34a-regulated bimodal switch targets Notch in colon cancer stem cells. Cell Stem Cell 12: 602-615, 2013.

35. Park EY, Chang E, Lee EJ, Lee HW, Kang HG, Chun KH, Woo YM, Kong HK, Ko JY, Suzuki H, et al: Targeting of miR34a-NOTCH1 axis reduced breast cancer stemness and chemoresistance. Cancer Res 74: 7573-7582, 2014.

36. Wu MY, Fu J, Xiao X, Wu J and Wu RC: MiR-34a regulates therapy resistance by targeting HDAC1 and HDAC7 in breast cancer. Cancer Lett 354: 311-319, 2014.

37. Li XJ, Ji MH, Zhong SL, Zha QB, Xu JJ, Zhao JH and Tang JH: MicroRNA-34a modulates chemosensitivity of breast cancer cells to adriamycin by targeting Notch1. Arch Med Res 43: 514-521, 2012.

38. Ghandadi $M$ and Sahebkar A: MicroRNA-34a and its target genes: Key factors in cancer multidrug resistance. Curr Pharm Des 22: 933-939, 2016.

39. Nie J, Ge X, Geng Y, Cao H, Zhu W, Jiao Y, Wu J, Zhou J and Cao J: miR-34a inhibits the migration and invasion of esophageal squamous cell carcinoma by targeting Yin Yang-1. Oncol Rep 34: 311-317, 2015.

40. Jones KB, Salah Z, Del Mare S, Galasso M, Gaudio E, Nuovo GJ, Lovat F, LeBlanc K, Palatini J, Randall RL, et al: miRNA signatures associate with pathogenesis and progression of osteosarcoma. Cancer Res 72: 1865-1877, 2012.

41. Maire G, Martin JW, Yoshimoto M, Chilton-MacNeill S, Zielenska M and Squire JA: Analysis of miRNA-gene expressiongenomic profiles reveals complex mechanisms of microRNA deregulation in osteosarcoma. Cancer Genet 204: 138-146, 2011

42. Cui X, Zhao Z, Liu D, Guo T, Li S, Hu J, Liu C, Yang L, Cao Y, Jiang J, et al: Inactivation of miR-34a by aberrant CpG methylation in Kazakh patients with esophageal carcinoma. J Exp Clin Cancer Res 33: 20, 2014.

43. Lin X, Xu XY, Chen QS and Huang C: Clinical significance of microRNA-34a in esophageal squamous cell carcinoma. Genet Mol Res 14: 17684-17691, 2015.

44. Choi JD and Lee JS: Interplay between epigenetics and genetics in cancer. Genomics Inform 11: 164-173, 2013.

45. Lodygin D, Tarasov V, Epanchintsev A, Berking C, Knyazeva T, Körner H, Knyazev P, Diebold J and Hermeking H: Inactivation of miR-34a by aberrant $\mathrm{CpG}$ methylation in multiple types of cancer. Cell Cycle 7: 2591-2600, 2008.

46. Chim CS, Wong KY, Qi Y, Loong F, Lam WL, Wong LG, Jin DY, Costello JF and Liang R: Epigenetic inactivation of the miR-34a in hematological malignancies. Carcinogenesis 31: 745-750, 2010.

47. Duffy MJ, Maguire TM, Hill A, McDermott E and O'Higgins N: Metalloproteinases: Role in breast carcinogenesis, invasion and metastasis. Breast Cancer Res 2: 252-257, 2000.

48. Samantaray S, Sharma R, Chattopadhyaya TK, Gupta SD and Ralhan R: Increased expression of MMP-2 and MMP-9 in esophageal squamous cell carcinoma. J Cancer Res Clin Oncol 130: 37-44, 2004.
49. Li Y, Ma J, Guo Q, Duan F, Tang F, Zheng P, Zhao Z and Lu G: Overexpression of MMP-2 and MMP-9 in esophageal squamous cell carcinoma. Dis Esophagus 22: 664-667, 2009.

50. Chen CF, Hsu EC, Lin KT, Tu PH, Chang HW, Lin CH, Chen YJ, $\mathrm{Gu}$ DL, Lin $\mathrm{CH}, \mathrm{Wu} \mathrm{JY}$, et al: Overlapping high-resolution copy number alterations in cancer genomes identified putative cancer genes in hepatocellular carcinoma. Hepatology 52: 1690-1701, 2010.

51. Tominaga K, Kondo C, Johmura Y, Nishizuka M and Imagawa $\mathrm{M}$ : The novel gene fad104, containing a fibronectin type III domain, has a significant role in adipogenesis. FEBS Lett 577: 49-54, 2004.

52. Nishizuka S, Ramalingam S, Spurrier B, Washburn FL, Krishna R, Honkanen P, Young L, Tsutomu S, Steeg PS and Austin J: Quantitative protein network monitoring in response to DNA damage. J Proteome Res 7: 803-808, 2008.

53. Cai C, Rajaram M, Zhou X, Liu Q, Marchica J, Li J and Powers RS: Activation of multiple cancer pathways and tumor maintenance function of the $3 \mathrm{q}$ amplified oncogene FNDC3B. Cell Cycle 11: 1773-1781, 2012.

54. Fan X, Chen X, Deng W, Zhong G, Cai Q and Lin T: Up-regulated microRNA-143 in cancer stem cells differentiation promotes prostate cancer cells metastasis by modulating FNDC3B expression. BMC Cancer 13: 61, 2013.

55. Lu Y, Yi Y, Liu P, Wen W, James M, Wang D and You M Common human cancer genes discovered by integrated geneexpression analysis. PLoS One 2: e1149, 2007.

56. Yang Y, Li D, Yang Y and Jiang G: An integrated analysis of the effects of microRNA and mRNA on esophageal squamous cell carcinoma. Mol Med Rep 12: 945-952, 2015.

57. Genovese G, Ergun A, Shukla SA, Campos B, Hanna J, Ghosh P, Quayle SN, Rai K, Colla S, Ying H, et al: microRNA regulatory network inference identifies miR-34a as a novel regulator of TGF- $\beta$ signaling in glioblastoma. Cancer Discov 2: 736-749, 2012.

58. Qiao P, Li G, Bi W, Yang L, Yao L and Wu D: microRNA-34a inhibits epithelial mesenchymal transition in human cholangiocarcinoma by targeting Smad4 through transforming growth factor-beta/Smad pathway. BMC Cancer 15: 469, 2015

59. Zhou Q, Dong Wang L, Du F, Zhou Y, Rui Zhang Y, Liu B, Wei Feng C, Gao SS, Fan ZM, Yang CS, et al: Changes of TGFbetal and TGFbetaRII expression in esophageal precancerous and cancerous lesions: A study of a high-risk population in Henan, northern China. Dis Esophagus 15: 74-79, 2002.

60. Chang TC, Wentzel EA, Kent OA, Ramachandran K, Mullendore M, Lee KH, Feldmann G, Yamakuchi M, Ferlito M, Lowenstein CJ, et al: Transactivation of miR-34a by p53 broadly influences gene expression and promotes apoptosis. Mol Cell 26: $745-752,2007$. 